\title{
Personality Structure: Who Cares?
}

\author{
Sanjay Srivastava
}

University of Oregon

A commentary to appear with:

Ashton, M. C., \& Lee, K. (in press). Objections to the HEXACO model of personality structure - and why those objections fail. European Journal of Personality.

Version date: April 20, 2020

Correspondence can be sent to sanjay@uoregon.edu. 


\begin{abstract}
Models of personality structure are not correct or incorrect. Instead, they are either useful or not for some purpose. As a result, a researcher's choice of a model will depend on their priorities. Possible priorities include maximizing variance accounted for, parsimony, crosslanguage generalizability, relevance to theory, and potential to synthesize across studies. Whether the HEXACO or any other model is "best" will depend on how much value a researcher places on each of these and other criteria.
\end{abstract}




\section{Personality Structure: Who Cares?}

Imagine asking three people to describe a computer. The first, a computer scientist, tells you it is a machine that carries out logical operations. The second, a repair technician, lists the components of a personal computer and their functions: a hard drive for data storage, a graphics card for driving the display, etc. The third, a college student, says it is a device you can use to read and post to social media, write papers, do statistics homework, or play online games. Which of these answers is "correct?" None of them and all of them. The computer scientist cares about algorithms, the technician about serviceable parts, the student about school and relationships. If one of those answers aligns with what you care about, it will be the right one for you.

All personality psychologists need to wrestle, implicitly or explicitly, with a similar question, sometimes called the units problem (Allport, 1958; Ozer, 1996). What concepts should we use to characterize personality? Should we focus on people's motives? Their unconscious conflicts? Their traits? And if it's the latter, which set of traits or trait dimensions should we use? When we answer the units question, our choice reflects our priorities. A model of personality structure is not correct or incorrect; instead it either is, or is not, useful for some purpose. The choice of a structural model reflects the beliefs and values of the researcher choosing it (Saucier \& Srivastava, 2015).

In the target article, Ashton and Lee (2020) consider whether the HEXACO is the best personality model. Their answer is yes. But who is asking and why? Sometimes questions about priorities are addressed explicitly; other times, the answers are assumed.

One priority might be to maximize how much variance in personality space is captured, or relatedly, variance in predicted outcomes. Ashton and Lee cite evidence that the HEXACO outperforms the Big Five in this regard. But if the only goal is prediction, there is no reason to 
care about scales at all: all of the information in scales is contained in the items, plus much more, and it is all grist for the algorithmic mill. Ashton and Lee have to invoke other priorities, like parsimony or interpretability, to make a case that it is worth scoring a smaller set of dimensions. Even then, the best choice will depend on the value assigned to different criteria. For example, they describe the greater variance explained by the BFAS than the HEXACO as "a bad trade-off between information and parsimony" (p. 13). Without a utility function to weigh the benefit of 0.44 more scales' worth of information against the cost of 4 variables less parsimony, that is more of an aesthetic judgment than a general answer.

Another priority might be cross-language generalizability. Unlike others, this one goes relatively unexamined in the target article; its importance is assumed. But why? A model that does a good job in a particular setting may sometimes be more useful than a generic model that ignores locally relevant differences. For example, gheirat is an important phenomenon in Iranian culture that has no direct translation to English. It is a distinctive set of thoughts, feelings, and actions associated with violations of namoos, a set of people and entities one feels protective toward (Razavi, Shaban-Azad, \& Srivastava, 2019). People who are prone to gheirat are described as ghairati, and in our work in progress, we find that they are ascribed a whole host of other traits. A researcher studying Iranians with the HEXACO, with its implicit value system that says that individual differences are only important if they appear in many languages, would leave it out. In so doing, they might miss something important in that context.

Another priority might be connection to theory. Notably, Ashton and Lee's case for the HEXACO is that was useful in making sense of a phenomenon one of them was studying, altruism. That is a reflection of one researcher's priorities. If a variable system offers an interesting set of concepts to help characterize a research problem, that is nothing to sneeze at. 
But usefulness is not deep truth. There is no reason to expect that any dimension reduction of natural-language descriptions will carve nature or anything else at its joints. Correlations are guaranteed to exist between any minimally valid behavioral variable and biological ones like genes or brain systems, for reasons that offer no promise of leading to an interesting or satisfying theory (Poldrack, 2010; Turkheimer, 1998). The same applies to correlations with psychological “process" variables (Saucier \& Srivastava, 2015; Srivastava, 2010; Wood, Gardner, \& Harms, 2015). Fiske (1994) asked of the Big Five, "Why 5, and not 3, 7, or 16? Why these five?” (p. 123). That question has never been satisfactorily answered, and there is no reason to expect that the HEXACO will fare better. Ashton and Lee's statement that it makes no difference whether the HEXACO dimensions are factors, composites, or network communities - each of which implies very different underlying mechanisms responsible for trait covariance - seems to be a tacit concession of this.

One more priority to mention is facilitating synthesis of results across studies. This was a great part of the Big Five's success (John \& Srivastava, 1999). Ashton and Lee appear to value it too in the way they argue for factor-level models over facets, though they might be careful offering PsycINFO hits as evidence - the Old Personality Psychologists Club might get a few ideas.

With all these things to consider, where do my own priorities lead me? When I don't have a good reason to do something else, I measure the Big Five in all its as-originally-rotated glory and add an H-factor scale. That makes it easy to line up my newest results with older ones, while gaining extra interesting information. This approach is not likely to make the purest partisans of either the HEXACO or the Big Five happy. As it turns out, that is not one of my priorities. 


\section{References}

Allport, G. W. (1958). What units shall we employ? In G. Lindzey (Ed.), Assessment of human motives (p. 239-260). New York: Rinehart.

Fiske, D. W. (1994). Two cheers for the Big Five! Psychological Inquiry, 5, 123-124.

John, O. P., \& Srivastava, S. (1999). The Big Five trait taxonomy: History, measurement, and theoretical perspectives. In L. A. Pervin \& O. P. John (Eds.), Handbook of personality: Theory and research (2nd ed., pp. 102-138). New York: Guilford.

Ozer, D. J. (1996). The units we should employ. Psychological Inquiry, 7(4), 360-363.

Poldrack, R. A. (2010). Mapping mental function to brain structure: How can cognitive neuroimaging succeed? Perspectives on Psychological Science, 5(6), 753-761.

Razavi, P., Shaban-Azad, H., \& Srivastava, S. (2019, February). Emotional Reactions to Violations of Honor: A Multi-Method Investigation of Gheirat in Iran. Poster presented at the Advances in Cultural Psychology preconference of the Society for Personality and Social Psychology in Portland, OR. Link: http://bit.ly/SPSP2019_PR

Saucier, G., \& Srivastava, S. (2015). What makes a good structural model of personality? Evaluating the Big Five and alternatives. In M. Mikulincer, P. R. Shaver, L. Cooper \& R. Larsen (Eds.), Handbook of Social and Personality Psychology (Vol. 4, pp. 283-305). Washington, DC: APA.

Srivastava, S. (2010). The Five-Factor Model describes the structure of social perceptions. Psychological Inquiry, 21, 69-75.

Turkheimer, E. (1998). Heritability and biological explanation. Psychological Review, 105(4), 782-791. 
Wood, D., Gardner, M. H., \& Harms, P. D. (2015). How functionalist and process approaches to behavior can explain trait covariation. Psychological Review, 122(1), 84-111. 